\title{
Early Prediction of Twin-to-Twin Transfusion Syndrome with the use of First Trimester Ultrasound Markers: Is it Possible?
}

\author{
Aristides Antsaklis, Vasileios Pergialiotis, Marianna Theodora, Vasileios Papazefkos, Panagiotis Antsaklis
}

\begin{abstract}
Background: The incidence of multifetal gestation and particularly of twin pregnancy has raised as a result of the introduction of assisted reproduction techniques (ART). Twinto-twin transfusion syndrome (TTTS) is a serious complication observed in monochorionic pregnancies producing severe morbidity and ultimately resulting in loss of one or all fetuses. We assessed the potential of early prediction of TTTS among three markers screened early in pregnancy [nuchal translucency (NT)] and its discrepancy and discordance, crown-rump length $(\mathrm{CRL})$ and its discrepancy and discordance among twins and ductus venosus (DV) Doppler abnormalities.
\end{abstract}

\begin{abstract}
Materials and methods: We conducted a systematic review searching Medline (1966-2011) and Scopus (2004-2011) engines, as well as reference lists from all included studies. Twelve studies were finally enrolled in the present review, including seven prospective studies, three prospective studies and one that could not be defined either as prospective or retrospective.
\end{abstract}

Conclusion: It seems that DV Doppler may denote this syndrome's possible future development and should be assessed early in monochorionic pregnancies. Further studies are definitely needed in order to evaluate the place of $C R L$ and NT discrepancy and discordance in predicting TTTS.

Keywords: Twin-twin transfusion, Ductus venosus, Crown-rump length discrepancy, Nuchal translucency discrepancy.

How to cite this article: Antsaklis A, Pergialiotis $V$, Theodora M, Papazefkos V, Antsaklis P. Early Prediction of Twin-to-Twin Transfusion Syndrome with the use of F irst Trimester Ultrasound Markers: Is it Possible? Donald School J Ultrasound Obstet Gynecol 2013;7(1):66-72.

\section{Source of support: Nil}

Conflict of interest: None declared

\section{INTRODUCTION}

Multifetal gestation is the result of either fertilization of separate ova, or less frequently of the division of a single fertilized ovum. When normally conceived, according to Hellin's law one twin pregnancy is anticipated in every 89 pregnancies, one triplet pregnancy once in $89^{2}$ and quadruplets once in $89 .{ }^{3} \mathrm{~T}$ win pregnancies are divided either in dizygotic (when two fertilized ova are inserted in the uterus) or monozygotic pregnancies (when a single fertilized ovum divides). Dizygotic pregnancies account for $67 \%$ of twin pregnancies, while monozygotic pregnancies occupy the rest $33 \%$. M onozygotic pregnancies are further divided according to chorion separation to either dichorionic or monochorionic and monochorionic pregnancies are subsequently divided according to amnion separation to either diamniotic or monoamniotic. Taylor et al describe that monochorionic placentation is the commonest abnormality presented during pregnancy with an incidence of 1 in every 400, that is far more common than fetal malformations. ${ }^{1}$

The incidence of multifetal gestation and particularly of twin pregnancy has raised since 1970 as a result of the introduction of assisted reproduction techniques (ART). While the birth rate of monozygotic twins remains constant worldwide, it seems that dizygotic pregnancies vary among different races with higher prevalence in women of A frican origin and lower among women of A sian ethnicity.

Generally, multifetal gestation is considered a high risk pregnancy. Complication rates are higher than singleton pregnancies for the occurrence of hyperemesis gravidarum, gestational anemia, hypertensive disorders including preeclampsia, premature rupture of the membranes, placental abruption, intrauterine growth restriction, preterm labor, polyhydramnios and obstetrical complications during delivery (such as malpresentation, cord entanglement, placental abruption, operative delivery, cesarean section).

Specifically monochorionic pregnancies are considered as high risk when compared to singleton and dizygotic pregnancies, due to the increased risk of birth weight discordance, fetal growth restriction and preterm labor. Furthermore, almost all monochorionic twin placentae are associated with interfetal anastomoses. Twin-to-twin transfusion syndrome (TTTS) refers to the pathologic entity of intrauterine blood transfusion from one (donor) to another (recipient) twin when these anastomoses fail to balance among the two circulations. TTTS is divided according to Quintero criteria in five stages ranging from low risk to high risk. ${ }^{2}$

Recipient twin usually develops hypervolemia that leads to congestive heart failure leading to abnormal Doppler patterns in various vessels including ductus venosus (DV) and umbilical vein and in heart abnormalities such as tricuspid regurgitation. $\mathrm{O} n$ the other hand the donor twin is suffering from hypovolemia that seems to correlate with significant reduction of blood flow velocities, presented in 
Early P rediction of Twin-to-Twin Transfusion Syndrome with the use of First Trimester Ultrasound Markers: Is it P ossible?

\begin{tabular}{|c|c|c|c|c|}
\hline Database & earch terms & Date of final search & Citations retrieved & Articloc included \\
\hline Medline (1966-2011) & $\begin{array}{l}\text { Nuchal and TTTS, CRL and } \\
\text { TTTS, (ductus or DV) and } \\
\text { TTTS limits: Humans, English, } \\
\text { publication Date from } 1997\end{array}$ & 27.10 .2012 & 216 & 11 \\
\hline Scopus (2004-2011) & $\begin{array}{l}\text { Nuchal and TTTS, CRL and } \\
\text { TTTS, (ductus or DV) and } \\
\text { TTTS limits: Humans, English, } \\
\text { publication Date from } 1997\end{array}$ & 27.10 .2012 & 223 & 0 \\
\hline $\begin{array}{l}\text { R eferences of included } \\
\text { articles }\end{array}$ & & 27.10 .2012 & 1 & 1 \\
\hline $\begin{array}{l}\text { Total after removing } \\
\text { duplicates }\end{array}$ & & $\mathrm{N} / \mathrm{A}$ & 224 & 12 \\
\hline
\end{tabular}

Doppler studies as increased placental resistance that consecutively increases cardiac afterload and decreases venous return. Furthermore, early studies suggest that early fetal cardiac failure during the first weeks of pregnancy may lead to increased nuchal translucency (NT).

\section{AIM OF THE STUDY}

TTTS is a serious complication observed in monochorionic pregnancies producing severe morbidity and ultimately resulting in loss of one or all fetuses. Early prediction could lead to acquisition of treatment strategies in order to prevent its serious forms. We conducted a systematic review and assessed the potential of early prediction of TTTS among three markers screened early in pregnancy NT and its discrepancy among twins, crown-rump length $(C R L)$ and its discrepancy among twins and DV D oppler abnormalities.

\section{MATERIALS AND METHODS}

\section{Literature Search and Study Selection}

We searched M edline (1966-2011) and Scopus (2004-2011) search engines, as well as reference lists from all included studies. Sebire et al firstly described higher NT discrepancies among twins developing TTTS than normal controls, ${ }^{3}$ thus study search was limited thereafter. Search strategies are described in Table 1, while article flow is presented in Figure 1.

\section{Eligibility Criteria, Data Extraction and Definitions}

We decided to include all cohort studies (prospective and retrospective) and randomized control trials without taking in mind the number of patients and the expertize of doctors performing first trimester screening ultrasonography. Plain English language and humans were the only filters entered during search.

Discordance was defined as the ratio of intertwin NT or CRL discrepancy/NT or CRL of the recipient twin.

A single author (Dr Pergialiotis) extracted information from included studies in a structured form, including descriptive characteristics and final results (T able 2).

\section{RESULTS}

Twelve studies were finally enrolled in the present review, including seven prospective studies, three prospective

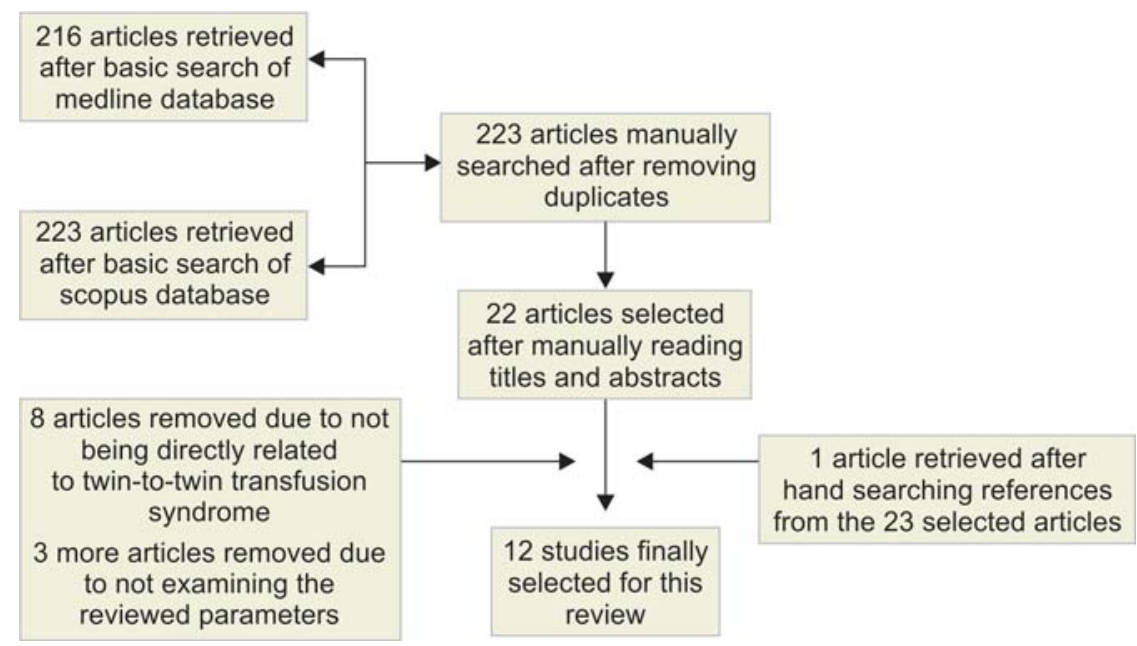

Fig. 1: Plot of search strategy 
Table 2: Study characteristics and results

\begin{tabular}{|c|c|c|c|}
\hline Date; Author & Type of study & $\begin{array}{l}\text { Number and descriptive } \\
\text { characteristics of participants }\end{array}$ & Results \\
\hline 2000; Mattias & $\mathrm{N} / \mathrm{A}$ & $\begin{array}{l}\text { Eleven monochorionic diamniotic } \\
\text { pregnancies that presented in } \\
\text { the first trimester (weeks: 11-14th). } \\
\text { Two of them developed TTTS. }\end{array}$ & $\begin{array}{l}\text { Two women identified with TTTS in } \\
\text { whom DV had a reversed A-wave (all } \\
\text { other with normal DV Doppler). NT } \\
\text { was not assessed statistically. }\end{array}$ \\
\hline 2000; Sebire & Retrospective cohort & $\begin{array}{l}\text { Three hundred and three cases of } \\
\text { monochorionic diamniotic pregnancies } \\
\text { that presented in the first trimester } \\
\text { (weeks: 11-14). Forty-three of them } \\
\text { developed severe TTTS. }\end{array}$ & $\begin{array}{l}\text { Increased NT thickness ( }>95 \% \text { ) was } \\
\text { found in significantly higher } \\
\text { prevalence among the TTTS group } \\
\text { ( } 17.4 \% \text { of fetuses and } 28 \% \text { of } \\
\text { pregnancies) compared to the } \\
\text { non-TTTS group ( } 6.6 \% \text { of fetuses } \\
\text { and } 10.2 \% \text { of pregnancies) ( } p<0.001 \text { ). } \\
\text { Likelihood ratio of increased NT for } \\
\text { the development of subsequent } \\
\text { TTTS was } 3.5 \text {. }\end{array}$ \\
\hline
\end{tabular}

2006:S ueters Prospective observational

2007; El Kateb

Prospective observational

2007; Kagan

Prospective observational

2007; S perling

Prospective multicenter observational

2008: Casasbuenas Retrospective cohort
Twenty-three monochorionic pregnancies monitored from the first trimester. Four of them presented with TTTS.

Two hundred monochorionic pregnancies that presented in the first trimester (weeks: 11-14) divided in three subgroups, (1) 103 consecutive monochorionic diamniotic pregnancies prospectively studied, (2) one hundred and thirty-six nonconsecutive monochorionic diamniotic pregnancies including 64 cases of TTTS studied retrospectively and (3) group of 100 consecutive cases of TTTS studied retrospectively.

Five hundred and twelve monochorionic pregnancies that presented in the first trimester (weeks: 11-13 ${ }^{+6}$ ). One hundred cases of them later developed TTTS, 58 requiring endoscopic laser surgery,

19 with death of one or both fetuses at 13-18 weeks and 23 with death of one or both fetuses at 21-38 weeks. trimester (weeks: 12-14 ${ }^{+6}$ ), 15 diamniotic and two monoamniotic.

Thirty monochorionic diamniotic pregnancies (27 twin and three triplets involving two diamniotic fetuses each) that presented in the first trimester (weeks: 11-14). TTTS occurred in six pregnancies.

Five hundred and sixteen dichorionic and 179 monochorionic pregnancies
NT thickness not associated with development of TTTS although statistical analysis not performed. Ductus venosus normal Doppler in all fetuses with TTTS.

CRL discordance of $>10 \%$ and NT $>95$ or $<5 \%$ not related to TTTS development (group 1 analysis). Same conclusions in group 2. $C R L$ discordance of $>10 \%$ had a positive correlation with early TTTS development ( $<20$ weeks). NT had no correlation with age at diagnosis. Neither of the two parameters was correlated with staging of TTTS at diagnosis.

Nuchal translucency discordance among normal, laser treated and early fetal death was 11.1, 22.2 and $35.3 \%$ respectively (statistically significant differences in the prediction of severe TTTS needing therapy and early fetal death).

$C R L$ discordance among normal, laser treated and early fetal death was $3.6,6.0$ and $5.9 \%$ respectively (statistically significant differences in the prediction of severe TTTS needing therapy and early fetal death).

No correlation of NT discordance and TTTS $(43 \%$ of TTTS patients vs $45 \%$ of non-TTTS with a discordance among twins of more than $0.5 \mathrm{~mm}$ ).

No correlation between NT thickness was observed ( $20 \%$ of TTTS and $20 \%$ of normal fetuses had increased NT > 95\%). However, the authors conclude that although the sensitivity of the method was poor in predicting pregnancy outcomes its specificity is high as no pregnancy with normal outcomes had increased NT. Discrepancies of NT and CRL although indexed in this study were not analyzed.

Nuchal translucency discordance among non-TTTS cases and TTTS observational 
Early P rediction of Twin-to-Twin Transfusion Syndrome with the use of First Trimester Ultrasound Markers: Is it P ossible?

Contd...

\begin{tabular}{|c|c|c|c|}
\hline Date; Author & Type of study & $\begin{array}{l}\text { Number and descriptive } \\
\text { characteristics of participants }\end{array}$ & Results \\
\hline & & $\begin{array}{l}\text { that presented in the first trimester } \\
\left.\text { (weeks: } 11-13^{+6}\right) \text {. Twenty-six developed } \\
\text { severe TTTS leading to endoscopic laser } \\
\text { therapy in } 24 \text { of them and to death prior to } \\
\text { therapy in two of them. }\end{array}$ & $\begin{array}{l}\text { cases was } 16.7 \text { and } 19.6 \%(p= \\
0.780) \text {. The prevalence of reversed } \\
\text { A-wave flow in the DV among TTTS } \\
\text { pregnancies was } 38.5 \% \text { and among } \\
\text { normal pregnancies } 10.9 \%(p<0.008) \text {. }\end{array}$ \\
\hline 2010; Mattias & $\begin{array}{l}\text { Prospective } \\
\text { observational }\end{array}$ & $\begin{array}{l}\text { Ninety-nine monochorionic diamniotic } \\
\text { twin pregnancies that presented in the } \\
\text { first trimester (weeks } 11 \text {-14). } \\
\text { TTTS developed at } 12 \text { pregnancies }\end{array}$ & $\begin{array}{l}\text { CRL discrepancy among TTTS vs } \\
\text { controls was not statistically significant } \\
\text { ( } 3.54 \text { vs } 2.88, p=0.458 \text { ). NT } \\
\text { discrepancy was statistically } \\
\text { significant ( } 1.03 \text { vs } 0.27, p=0.003 \text { ). } \\
\text { Authors also presented CRL and NT } \\
\text { discordance with NT discordance being } \\
\text { statistically significantly enlarged in } \\
\text { TTTS cases, although CRL discordance } \\
\text { failed to be significantly enlarged. } \\
\text { Abnormal DV flow among TTTS and } \\
\text { non-TTTS cases was found statistically } \\
\text { significant ( } p<0.001 \text { ). RR for NT } \\
\text { discrepancy and abnormal DV flow } \\
\text { were calculated to be } 1.61 \text { and } 15.5 \\
\text { respectively. }\end{array}$ \\
\hline 2011; Fratelli & Prospective cohort & $\begin{array}{l}\text { One hundred and thirty-five } \\
\text { monochorionic, diamniotic twin pregnancies } \\
\text { that presented in the first trimester } \\
\text { (weeks: } 11-13^{+6} \text { ). TTTS occurred in } \\
16 \text { pregnancies. }\end{array}$ & $\begin{array}{l}\text { Median NT discordance was } 15 \% \text { in } \\
\text { TTTS pregnancies and } 14 \% \text { in } \\
\text { uncomplicated pregnancies ( } p=0.08 \text { ). } \\
\text { Only one TTTS complicated and two } \\
\text { uncomplicated fetuses had a NT }>95 \% \text {. } \\
\text { CRL discordance was } 4 \% \text { in TTTS } \\
\text { pregnancies and } 4 \% \text { in uncomplicated } \\
\text { pregnancies ( } p=0.35 \text { ). }\end{array}$ \\
\hline 2011; Memo & Retrospective cohort & $\begin{array}{l}\text { Two hundred and forty-two monochorionic } \\
\text { pregnancies that presented in the first } \\
\text { trimester. One hundred and two of them } \\
\text { were complicated by TTTS. }\end{array}$ & $\begin{array}{l}C R L \text { discrepancy among TTTS vs } \\
\text { controls was not statistically significant } \\
\text { ( } 3.83 \text { vs } 3.51, p=0.12 \text { ). NT discrepancy } \\
\text { among TTTS versus controls was not } \\
\text { statistically significant ( } 16.65 \text { vs } 14.75 \text {, } \\
p=0.869 \text { ). }\end{array}$ \\
\hline
\end{tabular}

studies and one that could not be defined either as prospective or retrospective. ${ }^{4-14}$ One study was not included in the final tabulation because we decided to include only its extended form. ${ }^{3}$ In another possibly similar case we included both studies as in the second one the author did not described it as an extended form of its precedent. Of particular note is the fact that three of the included studies were conducted in the same hospital, something that leads to the assumption that the two of them were extended forms of the first one.

Heterogeneity among indices used in included studies in order to estimate TTTS formation makes difficult their proper tabulation. While some studies use intertwin discordance in $C R L$ and NT, others seem to evaluate CRL discrepancies of more than $10 \%$ and NT measurements of more than the 95th percentile or less than the 5 th percentile. In a single study NT and CRL discordances were described as intertwin ratios.

\section{CRL Discordance/Discrepancy}

In overall CRL discordance was found to be significantly higher in TTTS fetuses in one study, ${ }^{8}$ while EI K ateb et al comment in the third arm of their study that when the intertwin CRL discordance was more than $10 \%$ it had a positive correlation with early TTTS development (prior to 20 weeks). ${ }^{7}$ Three studies failed to find statistical significance among intertwin CRL discordance and TTTS devel opment including the first two arms of the study of EI $\mathrm{K}$ ateb. ${ }^{7,12,13}$ Two more studies also failed to identify statistical significance in CRL discrepancy. ${ }^{12,14}$

\section{NT Discordance/Discrepancy and NT Thickness}

NT discordance is described in five studies with two of them reporting statistically significant association with TTTS 8,12 and the other three arguing this observation. ${ }^{7,9} \mathrm{NT}$ discrepancy is described in two studies, ${ }^{12,14}$ one of them finding it significantly increased among TTTS twins. ${ }^{12}$ Finally NT thickness is described in three studies $5,6,10$ with only one of them reporting it significantly increased in TTTS. ${ }^{5}$ However in the study of Casabuenas et $\mathrm{al}^{10}$ the authors underline the observation that although this index had a poor sensitivity its negative predictive value specificity was $100 \%$. 


\section{Abnormal Doppler}

Two studies in the present review comment abnormal Doppler measurements of DV and strongly correlate them with the future development of TTTS. ${ }^{11,12}$

\section{DISCUSSION}

Blood vessels in the placental unit arise from angioblastic tissue with its precedent being the mesenchyme of the yolk sac, body stalk and chorion. Chorionic vessels in monochorionic pregnancies develop normally in arteriovenous pairs. With the completion of the 5th week the fetoplacental circulation is considered functional and during this period flow dynamic factors define the conversion of a vessel to artery or vein. Therefore, formation of new anastomoses is rare. ${ }^{15}$

TTTS results from an abnormal disequilibrium in vascular anastomoses of monochorionic placentas. While arterioarterial anastomoses (AAA) seem to present in the vast majority of these uncomplicated pregnancies (84\%), and usually lead to the development of mild forms of preeclampsia, it seems that venovenous anastomoses (VVA) are rarer in monochorionic placentas (only in 20\%). ${ }^{1}$ Furthermore, studies indicate that V V A are associated with both perinatal death and antenatal neurological sequelae. ${ }^{16}$ A recent pathology study in 935 placentas revealed that mortality was higher when AA A where absent $(42 \%)$ and lower in the presence of a single AAA (15\%). TTTS complicated pregnancies were highly likely to have a VVA. ${ }^{17}$

Intertwin CRL discrepancy and discordance would be normally expected due to the hypervolemia of the recipient fetus and the concurrent hypovolemia of the donor fetus. In our review however, significance of efficacy of either $C R L$ discrepancy or discordance among studies was controversial. In a recent study CRL discrepancy among dichorionic twins was found similar to the discrepancy expected in monochorionic twins. ${ }^{18}$ Furthermore, the same authors conclude that intertwin discrepancy of less than 20\% resulted in viable twin pregnancy in more than $97 \%$ of cases, whereas when intertwin discrepancy was more than $60 \%$ there were no cases of both twins remaining viable. In another study conducted in 507 twin pregnancies the 95th and 99th CRL discordance percentiles were 12.2 and 19.3\% respectively. ${ }^{19}$ These observations lead us to the assumption that intertwin discrepancies and discordances below a certain level should not be taken in mind regardless if they are statistically significant or not. Therefore future studies should focus in the actual definition of the 95th percentile of these indices in monochorionic pregnancies in order to further evaluate them as prognostic tools of TTTS.
NT is considered nowadays an efficient marker of predicting chromosomal abnormalities. When it is found increased in fetuses with normal karyotype after chorionic villus sampling, other structural defects, with cardiac defects as predominant, may be anticipated. A n early study by M ontenegro et al suggests that increased NT may be the consequence of early heart failure. ${ }^{20}$ Its assumption is based in the observed cardiac defects in fetuses with trisomy 21 and 18 that seem to present in about half of cases in the first case and about all in the second. In a more recent review by Haak et al this hypothesis although not definitely excluded it is argued from studies that report that increased NT formation cannot be explained solely from cardiac failure as it seems to present also in defects that do not result in cardiac failure (such as septal defects). ${ }^{21}$ In the same review alteration in the extracellular matrix and lymphatic abnormalities are hypothesized to construct a possible model of nuchal edema resulting in increased NT.

A ccording to a recent study fetal echocardiography may become in the future a useful adjunct in staging TTTS with specific attention to the recipient twin. It seems that hypervolemia leads the recipient twin to congestive heart failure and its heart is trying to compensate establishing hypertrophy in its cardiac muscle. Hypertrophic cardiomyopathy itself presents with features, such as ventricular hypokinesia, abnormal flows in DV, increased cardiothoracic ratio, atrioventricular valve regurgitation and other. ${ }^{22}$ A nother recent study suggests that diastolic pathology and specifically shorter tricuspid flow duration may be a distinctive marker of TTTS, distinguishing it from other complications arising in monochorionic-diamniotic twins. ${ }^{23}$

A bnormal flows in the DV have been associated with cardiac defects. A recent study discusses the predictive value of DV in predicting cardiac abnormalities during first trimester screening. ${ }^{24}$ Specifically reversed A-wave flow increases with increasing NT without any obvious association with certain cardiac abnormalities. Although, the underlying mechanism resulting in reversed A-flow is not yet fully understood, this study speculates that fetal heart is more susceptible in congestive heart failure due to its lower compliance. Increased afterload combined with early diastolic heart failure may ultimately lead to reversed A -wave patterns in the DV. W hat is particularly important is the fact that there are certain heart defects that are not associated with second or third trimester heart failure and that ultimately become apparent postnatal. This specific information is of great importance as it underlines that reverse A-flows during early pregnancy may mask as gestation advances, losing their possible predictive value. 
Early P rediction of Twin-to-Twin Transfusion Syndrome with the use of First Trimester Ultrasound Markers: Is it P ossible?

In our review, both studies that evaluated the predictive value of reversed $A$-wave of DV came to the result that this index is highly specific of early cardiac failure of the recipient twin.

\section{CONCLUSION}

In a recent systematic review on TTTS performed by the Society for M aternal-Fetal M edicine the authors conclude that several markers early in pregnancy are associated with the future development of the syndrome. ${ }^{25}$ In our belief, although early screening of TTTS is not yet adopted by institutions around the globe, it seems at least that DV Doppler may denote this syndrome's possible future development and should be assessed early in monochorionic pregnancies.

How ever, CRL discrepancy and discordance indices are not yet fully understood and although extreme values may predict fetal demise, it is our conviction that they should be carefully used as markers of TTTS, as it seems that their positive predictive values are low. Moreover, it could be more intriguing to evaluate the specificity and sensitivity of these later tests in predicting future weight discordance and the possibility of preterm labor, knowing that monochorionic pregnancies are more prone to these complications than TTTS itself. Future multicenter cohort studies are needed in order to define percentiles for these particular indices, in order to further evaluate their cutoff values (95th and 5th respectively) as predictive of TTTS. Finally, it seems that NT discrepancy or discordance face the same problems with their counterparts in $C R L$. Furthermore, when percentiles of NT were used they were not always associated with the syndrome. Further studies are definitely needed in order to evaluate the place of these indices in predicting TTTS.

\section{REFERENCES}

1. Taylor M J, Talbert D G, Fisk N M . M apping the monochorionic equator - the new frontier. Ultrasound Obstet Gynecol 1999;14:372-74.

2. Quintero RA, M orales WJ, Allen M H, Bornick PW, Johnson PK, K ruger M. Staging of twin-twin transfusion syndrome. J Perinatol 1999;19:550-55.

3. Sebire N J, D'Ercole C, Hughes K, Carval ho M, N icolaides KH. Increased nuchal translucency thickness at 10 to 14 weeks of gestation as a predictor of severe twin-to-twin transfusion syndrome. Ultrasound Obstet Gynecol 1997;10:86-89.

4. Matias $A$, M ontenegro $N$, A reias JC. A nticipating twin-twin transfusion syndrome in monochorionic twin pregnancy. Is there a role for nuchal translucency and ductus venosus blood flow evaluation at 11-14 weeks? Twin Res 2000;3:65-70.

5. Sebire NJ , Souka A, Skentou H, Geerts L, N icolaides K H. Early prediction of severe twin-to-twin transfusion syndrome. Hum Reprod 2000;15:2008-10.

6. Sueters M, M iddel dorp J M , L opriore E, O epkes D, K anhai H H, $V$ andenbussche FP. Timely diagnosis of twin-to-twin transfusion syndrome in monochorionic twin pregnancies by biweekly sonography combined with patient instruction to report onset of symptoms. Ultrasound Obstet Gynecol 2006;28:659-64.

7. EI K ateb A, N asr B, Nassar M, B ernard JP, Ville Y. Firsttrimester ultrasound examination and the outcome of monochorionic twin pregnancies. Prenat Diagn 2007;27: 922-25.

8. Kagan K O, Gazzoni A, Sepulveda-Gonzalez G, Sotiriadis A, $\mathrm{Nicolaides} \mathrm{KH}$. Discordance in nuchal translucency thickness in the prediction of severe twin-to-twin transfusion syndrome. Ultrasound Obstet Gynecol 2007;29:527-32.

9. Sperling L, K iil C, Larsen LU, et al. D etection of chromosomal abnormalities, congenital abnormalities and transfusion syndrome in twins. Ultrasound Obstet Gynecol 2007;29: 517-26.

10. Casasbuenas A, W ong A E, Sepulveda W. Nuchal translucency thickness in monochorionic multiple pregnancies: $V$ alue in predicting pregnancy outcome. J Ultrasound Med 2008;27: 363-69.

11. M aiz N, Staboulidou I, L eal A M, M inekawa R, N icolaides KH. Ductus venosus Doppler at 11 to 13 weeks of gestation in the prediction of outcome in twin pregnancies. Obstet Gynecol 2009;113:860-65.

12. M atias $A, M$ ontenegro $N, L$ oureiro $T$, et al. Screening for twintwin transfusion syndrome at 11-14 weeks of pregnancy: The key role of ductus venosus blood flow assessment. Ultrasound Obstet Gynecol 2010;35:142-48.

13. Fratelli N, Prefumo F, Fichera A, Valcamonico A, M arella D, Frusca $T$. N uchal translucency thickness and crown rump length discordance for the prediction of outcome in monochorionic diamniotic pregnancies. Early Hum Dev 2011;87:27-30.

14. Memmo A, Dias T, M ahsud-Dornan S, Papageorghiou AT, B hide A, Thilaganathan B. Prediction of selective fetal growth restriction and twin-to-twin transfusion syndrome in monochorionic twins. BJOG 2012;119:417-21.

15. Sebire NJ, Talbert D, Fisk NM. Twin-to-twin transfusion syndrome results from dynamic asymmetrical reduction in placental anastomoses: A hypothesis. Placenta 2001;22:383-91.

16. Hack KE, van Gemert MJ, Lopriore E, et al. Placental characteristics of monoamniotic twin pregnancies in relation to perinatal outcome. Placenta 2009;30:62-65.

17. Nikkels PG, Hack KE, van Gemert MJ. Pathology of twin placentas with special attention to monochorionic twin placentas. J Clin Pathol 2008;61:1247-53.

18. Bora SA, B ourne T, B ottomley C, Kirk E, Papageorghiou AT. Twin growth discrepancy in early pregnancy. Ultrasound Obstet Gynecol 2009;34:38-42.

19. Bhide A, Sankaran S, Sairam S, Papageorghiou AT, Thilaganathan $B$. R elationship of intertwin crown-rump length discrepancy to chorionicity, fetal demise and birth-weight discordance. Ultrasound Obstet Gynecol 2009;34:131-35.

20. Montenegro N, M atias A, A reias JC, Castedo S, Barros H. Increased fetal nuchal translucency: Possible involvement of early cardiac failure. Ultrasound Obstet Gynecol 1997;10: 265-68.

21. Haak MC, van Vugt J M. Pathophysiology of increased nuchal translucency: A review of the literature. Hum Reprod U pdate 2003;9:175-84

22. Bensouda B , Fouron J C, Raboisson M J , Lamoureux J, Lachance $C$, L educ $L$. Relevance of measuring diastolic time intervals in the ductus venosus during the early stages of twin-twin transfusion syndrome. Ultrasound Obstet Gynecol 2007;30: 983-87.

23. Moon-Grady AJ, Rand L, Gallardo S, Gosnell K, Lee H, Feldstein VA. Diastolic cardiac pathology and clinical twin- 
twin transfusion syndrome in monochorionic/diamniotic twins. A m J Obstet Gynecol 2011;205:279 el-e11.

24. Chelemen T, Syngelaki A, M aiz N, A llan L, Nicolaides KH. Contribution of ductus venosus Doppler in first-trimester screening for major cardiac defects. Fetal Diagn Ther 2011;29:127-34.

25. Simpson LL. Twin-twin transfusion syndrome. Am J Obstet Gynecol 2013;208:3-18.

\section{ABOUT THE AUTHORS}

\section{Aristides Antsaklis}

Professor, Director, 1st Department of Obstetrics and Gynecology A thens U niversity M edical School, A lexandra Hospital, A thens, G reece

Correspondence Address: 80, $V$ asilissis Safias A venue, $A$ thens 11528-G reece, e-mail: adeptobgyn@yahoo.gr

\section{Vasileios Pergialiotis}

Senior L ecturer, 1st D epartment of O bstetrics and Gynecology, A thens University M edical School, A lexandra Hospital, A thens, Greece

\section{Marianna Theodora}

Senior L ecturer, 1st D epartment of O bstetrics and Gynecology, A thens University M edical School, A lexandra Hospital, A thens, Greece

\section{Vasileios Papazefkos}

Consultant, 1st Department of Obstetrics and Gynecology, A thens University M edical School, A lexandra H ospital, A thens, Greece

\section{Panagiotis Antsaklis}

Lecturer, 1st Department of Obstetrics and Gynecology, A thens University M edical School, A lexandra Hospital, A thens, Greece 